Journal of Physical Science, Vol. 29(Supp. 2), 215-226, 2018

\title{
Esterification of Non-edible Oil Mixture in Reactive Distillation Column over Solid Acid Catalyst: Experimental and Simulation Study
}

\author{
Ratna Dewi Kusumaningtyas, ${ }^{1 *}$ Haniif Prasetiawan, ${ }^{1}$ Brylian Rizky Pratama, ${ }^{1}$ Dani Prasetya ${ }^{1}$ \\ and Anwaruddin Hisyam ${ }^{2}$
}

${ }^{1}$ Chemical Engineering Department, Faculty of Engineering, Universitas Negeri

Semarang, Kampus UNNES, Sekaran, Gunungpati, Semarang 50229, Indonesia ${ }^{2}$ Faculty of Chemical and Natural Resources Engineering, Universiti Malaysia Pahang, Lebuhraya Tun Razak, 26300 Kuantan, Pahang, Malaysia

*Corresponding author: ratnadewi.kusumaningtyas@mail.unnes.ac.id

Published online: 30 July 2018

To cite this article: Kusumaningtyas, R. D. et al. (2018). Esterification of non-edible oil mixture in reactive distillation column over solid acid catalyst: Experimental and simulation study. (2018). J. Phys. Sci., 29(Supp. 2), 215-226, https://doi.org/10.21315/ jps2018.29.s2.17

To link to this article: https://doi.org/10.21315/jps2018.29.s2.17

\begin{abstract}
Biodiesel is one of the promising energy alternatives to fossil fuel. Among the economical feedstocks of biodiesel is high free fatty acid (FFA) vegetable oil. Production of biodiesel from high FFA oils needs esterification reaction as the pre-treatment step. In this work, esterification reaction of high FFA non-edible oil mixture (used cooking oil, jatropha oil, and nyamplung seed oil) was conducted in reactive distillation (RD) column in the presence of solid acid tin(II) chloride catalyst. RD has potential to be applied at industrial scale. For this purpose, an accurate model is required to scale up the process, predict the RD performance and optimise the process. Experimental work, simulation study and validation were carried out in this work to determine the accurate model and simulation. In experimental work, esterification reaction was conducted by varying the reaction temperature and catalyst concentration. The simulation was performed using ASPEN PLUS V8.8 and validated with the experimental data. Based on the experiment, the optimum FFA conversion was $78.33 \%$, obtained at temperature of $60^{\circ} \mathrm{C}$ and catalyst concentration of $5 \%(w / w)$. The FFA conversion achieved from the simulation was $75.8 \%$. The proximity between the simulation and experimental data demonstrated that this simulation has accurately predicted the conversion of FFA with less than 5\% error.
\end{abstract}

Keywords: Biodiesel, multiple oil feedstocks, tin(II) chloride, reactive distillation, validation

(C) Penerbit Universiti Sains Malaysia, 2018. This work is licensed under the terms of the Creative Commons Attribution (CC BY) (http://creativecommons.org/licenses/by/4.0/). 


\section{INTRODUCTION}

Nowadays, fuel demand has increased in accordance with the increase of public need for transportation, industries, power plant, household and many other activities. The increasing fuel demand is not in line with the energy sources availability. Based on data, fuel oil consumption in Indonesia has exceeded its domestic production and petroleum resources are expected to be available until the next $10-15$ years from now. ${ }^{1}$ Due to the depleting fossil fuel reserves, the development of renewable energy resources is important. Renewable energy is generated from renewable resources and can be constantly replenished, such as sunlight, wind, geothermal and various forms of biomass (biofuel), etc. One of the promising biofuels is biodiesel, which can be applied as diesel-engine fuel. Biodiesel exhibits various advantages. For instance, it is clean, environmentally friendly, holds excellent fuel properties, and can be utilised in the diesel engine without any modification of the machine. ${ }^{2}$

Biodiesel is derived from vegetable oils or animal fats through chemical modification. The main compounds of vegetable oils and animal fats are triglycerides and free fatty acids (FFA). Biodiesel is produced through a chemical process by converting vegetable oils/animal fats into fatty acid methyl esters (FAME). ${ }^{3}$ In general, FAME (biodiesel) can be synthesised via two distinctive routes, i.e., (1) one-step process of alkaline-catalysed transesterification reaction of low FFA vegetable oils/fats using short-chain alcohols; or (2) two-step process of acidcatalysed esterification of high FFA vegetable oils/fats using short-chain alcohols followed by transesterification of triglycerides of the oils/fats. ${ }^{4}$ Esterification reaction is a pre-treatment to reduce the FFA content by converting it into FAME.

High FFA vegetable oils are cheap and non-edible. Hence, they are hardly ever employed for food production. Utilisation of high FFA non-edible oils for biodiesel production is beneficial since it can avoid the crops competition between energy and food needs. There are several studies of biodiesel synthesis using nonedible oils, such as jatropha oils, rubber seed oils, used cooking oils, nyamplung (Calophyllum inophyllum L.) seed oils, palm fatty acid distillate, etc. ${ }^{3-8}$ However, the current studies of biodiesel production are predominated by the application of a single type of oil feed-stocks. For the purpose of feedstock diversification, study on the employment of multiple oil feed-stocks for biodiesel production is essential, thus it should be further investigated.

In this study, a mixture of three different oils were used as a feedstock in biodiesel production. The three oil sources used were cooking oil, jatropha oil and nyamplung seed oil, which contain high FFA. Used cooking oil might harm the environment if 
it is not properly managed. One of the solutions is by processing it into biodiesel. On the other hand, jatropha and nyamplung seed oils are among the high FFA nonedible oils which are potential as biodiesel feedstocks. ${ }^{3,7}$

Biodiesel production is challenging since the process usually involves a reactor followed by a series of separation equipment, which contributes to the complexity and expensive cost of biodiesel production. This challenge can be overcome by the application of multi-functional reactors such as reactive distillation (RD) ${ }^{4}$ $\mathrm{RD}$ integrates reaction and separation (distillation) in a single column. Thus, it offers many advantages compared with the reactor-separator in terms of the increase in selectivity and conversion, better heat control, reduction of the catalyst consumption, azeotrope avoiding, the effectiveness of heat integration for energy conservation, and lower capital cost due to the reduction of distillation columns as separation unit. Moreover, $\mathrm{RD}$ is suitable for reversible reaction such as esterification process since continuous product separation on RD will shift the reaction equilibrium towards product formation. ${ }^{9}$

In this study, $\mathrm{RD}$ was used for conducting esterification reaction of high FFA vegetable oil mixture as the pre-treatment step of biodiesel production. Esterification reaction was performed using methanol in the presence of tin(II) chloride solid catalyst. RD is potential for industrial-scale application. However, to scale up the process, predict the RD performance, and optimise the process at large scale operation, an accurate simulation is needed. Hence, this work will focus on the investigation of the accurate simulation of RD process. The investigation involved experimental work, simulation study and validation. In the experimental work, effects of reaction temperature and catalyst concentration were studied on the FFA conversion. Subsequently, a simulation study was carried out based on the equilibrium model (MESH) using ASPEN PLUS V8.8. ${ }^{4}$ Several kinetic parameters used in the simulation were obtained from previous study performed by Kusumaningtyas. ${ }^{10}$ The process simulation was then validated using the FFA conversion obtained in the experiment. Validation is important since the proximity between the simulation result and the experimental data would indicate that the model and simulation can be applied for the prediction of $\mathrm{RD}$ performance at the larger (industrial) scale of process. 


\section{EXPERIMENTAL}

\subsection{Materials}

The feedstock used in this study is a mixture of non-edible oil which consists of jatropha oil, nyamplung seed oil and used cooking oil. Used cooking oil was collected from home industry Roti Goreng Anggita in Sruweng, Kebumen, Jawa Tengah, Indonesia with FFA content of $15.05 \%$. Crude jatropha oil with FFA content of $30.57 \%$ was obtained from PT Jatropha Green Energy, Kudus, Jawa Tengah, Indonesia. Nyamplung seed oil with FFA content of $26.37 \%$ was obtained from Koperasi Jarak Lestari, Cilacap, Jawa Tengah, Indonesia. Methanol $(99 \% \mathrm{v} / \mathrm{v})$ and solid acid catalyst tin(II) chloride with purity of $99 \%$ were obtained from Merck.

\subsection{Esterification Reaction}

The apparatus employed for the experiments was composed of the main RD column and the pre-mixer tank combined with pre-heater. The RD column was a Raschig ring packed column equipped with an electrical heating mantle. A condenser and reboiler were placed on the top and bottom of the column, respectively. Esterification reaction of non-edible oil mixture was performed in this RD and the schematic drawing of the equipment is shown in Figure 1.

Non-edible oil mixture which consists of used cooking oil, jatropha oil and nyamplung seed oil with a ratio of $1: 1: 1(\mathrm{v} / \mathrm{v})$ was reacted with methanol. Oil to methanol molar ratio in this study was 1:60. Previously, tin(II) chloride with certain concentration was diluted in methanol. Oil mixture and catalyst-methanol solution were then preheated and pre-mixed before entering RD column. In this study, esterification reactions were conducted at $40^{\circ} \mathrm{C}, 50^{\circ} \mathrm{C}$ and $60^{\circ} \mathrm{C}$. Tin(II) chloride concentrations were varied at $1 \%, 3 \%, 5 \%, 7 \%$ and $9 \%(\mathrm{w} / \mathrm{w})$ of oil. The product was then collected continuously at the bottom of RD for further analysis. 


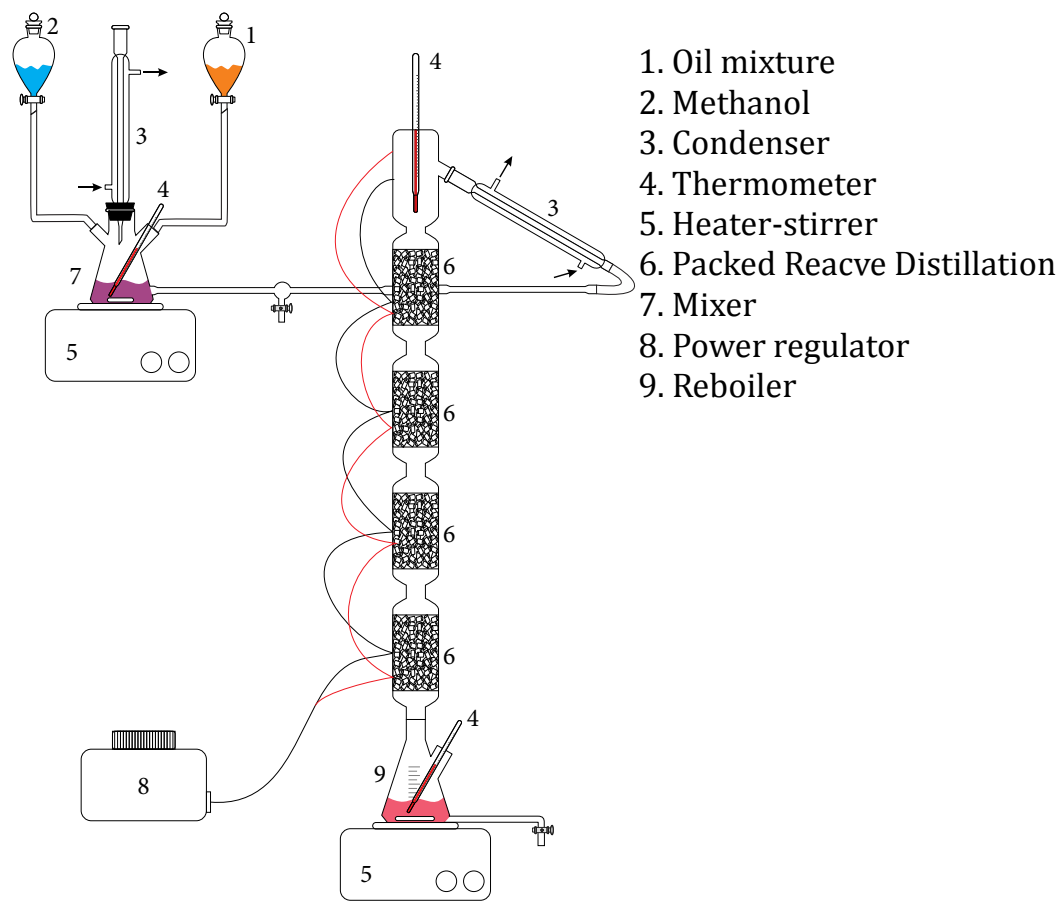

Figure 1: Reactive distillation apparatus.

\subsection{Analytical Procedure}

Reaction conversions were estimated from FFA content by $\mathrm{KOH}$ titration. ${ }^{8,9}$ The sample was first diluted using ethanol 99.9\%. Subsequently, it was titrated using $\mathrm{KOH}$ 0.1 M. Acidity was calculated by using the following calculation:

$$
a=\frac{v_{\text {titration. }} M r \text { FFA.M } M O H}{m \text { sample.1000 }}
$$

where $a$ = activity index, $v_{\text {titration }}=$ titrant volume $(\mathrm{ml}), M r F F A=$ molecular weight of free fatty acid, $M K O H=\mathrm{KOH}$ concentration $\left(\mathrm{ml} \mathrm{l}^{-1}\right)$, and $m_{\text {sample }}=$ mass of the sample $(\mathrm{g})$.

The conversion was then calculated using Equation 2:

$$
X_{A}=\frac{a_{i}-a_{t}}{a_{i}} \times 100 \%
$$

where $X_{A}=$ FFA conversion, $a_{i}=$ initial acidity index, and $a_{t}=$ acidity index at $t$ time. 


\subsection{Simulation Setup}

$\mathrm{RD}$ simulation was carried out using a chemical process simulator (ASPEN Plus $\mathrm{V}$ 8.8). The RADFRAC steady-state model was used for the RD column. RADFRAC is a rigorous equilibrium stage model which is able to solve the set of equations that describe each equilibrium stage: material balances, phase equilibrium relationship between the vapour and the liquid leaving the stage, summation equation and heat balance. The phase equilibrium was described by assuming the vapour phase as ideal gas and the liquid phase as real solution, on the basis of the UNIQUAC model as it was suggested by Bhatia et al. ${ }^{11}$

Esterification reaction between fatty acid and methanol can be represented as:

$$
\mathrm{RCOOH}+\mathrm{CH}_{3} \mathrm{OH} \underset{k_{2}}{\stackrel{k_{1}}{\rightleftharpoons}} \mathrm{RCOOCH}+\mathrm{H}_{2} \mathrm{O}
$$

The reaction rate can be written as:

$$
\begin{aligned}
& -\frac{d C_{A}}{d t}=k_{1} C_{A} C_{B}-k_{2} C_{C} C_{D} \\
& k_{i}=k_{0 i} \exp \left(-E_{a i} / R T\right)
\end{aligned}
$$

where $C_{A}=$ the concentrations of oleic acid (mole $\left.1^{-1}\right), C_{B}=$ the concentrations of methanol (mole 1-1), $C_{C}=$ the concentrations of methyl oleate (mole $\left.1^{-1}\right), C_{D}=$ the concentrations of water $\left(\mathrm{mole} \mathrm{l}^{-1}\right), k_{l}=$ kinetic rate constants for forward reaction $\left(1 \mathrm{~mole}^{-1} \mathrm{~min}^{-1}\right), k_{2}=$ kinetic rate constants for backward reaction $\left(1 \mathrm{~mole}^{-1}\right.$ $\left.\min ^{-1}\right), \mathrm{k}_{0 \mathrm{i}}=$ the pre-exponential factor $\left(\mathrm{min}^{-1}\right)$, and $E_{a i}=$ activation energy for kinetic reaction $\left(\mathrm{kJ} \mathrm{mole}^{-1}\right)$.

The kinetic rate constants in this work were obtained from the experimental study performed by Kusumaningtyas et al. as presented in Table $1 .{ }^{9}$ Whereas, the feed inlet composition and parameters for RD simulation are presented in Table 2 and Table 3, respectively. 
Table 1: Kinetic and thermodynamic parameters of the reacting system.

\begin{tabular}{lll}
\hline Parameter & Value & \\
\hline $\mathrm{k}_{1}$ & $2.33 \times 10^{10}$ & $\mathrm{l}^{-1} \mathrm{~mole}^{-1} \mathrm{~min}^{-1}$ \\
$\mathrm{Ea}_{1}$ & 64.5 & $\mathrm{~kJ} \mathrm{~mole}^{-1}$ \\
$\mathrm{k}_{2}$ & $4.29 \times 10^{8}$ & $\mathrm{l}^{-1} \mathrm{~mole}^{-1} \mathrm{~min}^{-1}$ \\
$\mathrm{Ea}_{2}$ & 40.7 & $\mathrm{~kJ}$ mole \\
$\mathrm{T}$ boil methanol & 64.7 & ${ }^{\circ} \mathrm{C}$ \\
Kusumaningtyas et al. & & \\
\hline
\end{tabular}

Table 2: Feed inlet composition for RD simulation.

\begin{tabular}{ll}
\hline Component & Input $\left(\mathrm{kmole}^{-1}\right)$ \\
\hline Oleic acid & 0.0421 \\
Linoleic acid & 0.02 \\
Palmitic acid & 0.0291 \\
Stearic acid & 0.009 \\
Methanol & 6.012 \\
\hline Total & 6.1122 \\
\hline
\end{tabular}

Table 3: Parameters for the RD simulation.

\begin{tabular}{ll}
\hline Parameter & Value \\
\hline Number of stage & 20 \\
Reaction zone & 13 \\
Input feed zone & 7 \\
Feed temperature & $50^{\circ} \mathrm{C}$ \\
Total feed & $6.112 \mathrm{kmole}^{-1}$ \\
Pressure & Atmospheric \\
Condenser type & Total \\
Reboiler type & Kettle \\
\hline
\end{tabular}

\section{RESULTS AND DISCUSSION}

The experimental work was conducted to study the effects of reaction temperature and catalyst concentration on the FFA conversion. The simulation was then performed based on the equilibrium model (MESH) using ASPEN PLUS V8.8. Simulation result was compared with the experimental data to examine the proximity of the values and validate the simulation. 


\subsection{Effect of Temperature on FFA Conversion}

Effect of reaction temperature on the reaction conversion was studied at temperatures $40^{\circ} \mathrm{C}, 50^{\circ} \mathrm{C}$ and $60^{\circ} \mathrm{C}$. Table 4 shows the effect of reaction temperature to the FFA conversion at different catalyst concentrations. It can be seen that at catalyst concentration of $1 \%, 3 \%$ and $5 \%$, the increasing temperature also increases the FFA conversion. This phenomenon was in accordance with the research carried out by Supardan and Satriana which found that the optimum reaction temperature for esterification process was at $60^{\circ} \mathrm{C} . .^{12}$ It also corresponded with the theory of molecule kinetics stating that a temperature increase will raise the molecule kinetics and the effectiveness of molecule collisions. This phenomenon will lead to a faster reaction and increase the conversion. ${ }^{13}$ FFA conversions at different temperatures are presented in Table 4.

Table 4: Effect of reaction temperature at different catalyst concentration.

\begin{tabular}{ccccc}
\hline \multirow{2}{*}{ No } & Catalyst $(w / w)$ & \multicolumn{3}{c}{ Conversion (\%) } \\
\cline { 3 - 5 } & $1 \%$ & at $40^{\circ} \mathrm{C}$ & at $50^{\circ} \mathrm{C}$ & at $60^{\circ} \mathrm{C}$ \\
\hline 1 & $3 \%$ & 66.57 & 70.17 & 75.14 \\
2 & $5 \%$ & 67.86 & 72.20 & 77.95 \\
3 & $7 \%$ & 69.15 & 74.72 & 78.33 \\
4 & $9 \%$ & 74.29 & 69.15 & 68.12 \\
5 & 65.59 & 65.29 & 61.76 \\
\hline
\end{tabular}

Different trends were exhibited at the catalyst concentrations of $7 \%$ and $9 \%$. As the temperature increased, FFA conversion at certain catalyst concentration was decreasing. This is due to a large amount of catalyst used in the esterification process. With a large amount of catalyst, several parts of the catalyst cannot be completely dissolved in the reactant mixture. The insoluble catalyst will become a phase barrier which will prevent mass transfer process and results in the declining FFA conversion. According to Ferreira et al., the optimum condition for esterification reaction of FFA using tin(II) chloride catalyst will be achieved when the mixture of reactants and catalyst is in homogeneous phase. ${ }^{14}$

\subsection{Effect of Catalyst Concentration on the FFA Conversion}

A slow and reversible reaction such as esterification process needs a catalyst to increase the reaction rate. The larger the amount of catalyst employed in a process, the more active sites available to accelerate the reaction as reported by Srilatha et al. ${ }^{15,16}$ In the esterification of FFA by methanol, a large excess of tin(II) chloride 
catalyst will cause side reactions between tin(II) chloride with methanol to form alkyl halide which has blackish colour on the product. This reaction also decreases the amount of methanol and will affect the reactants molar ratio. The decreasing amount of methanol also causes slower reaction rate as stated by Ramadhas et al. ${ }^{5}$ Figure 2 demonstrates that the optimum FFA conversion is $78.33 \%$, obtained at the reaction temperature of $60^{\circ} \mathrm{C}$ with the catalyst concentration of $5 \%$.

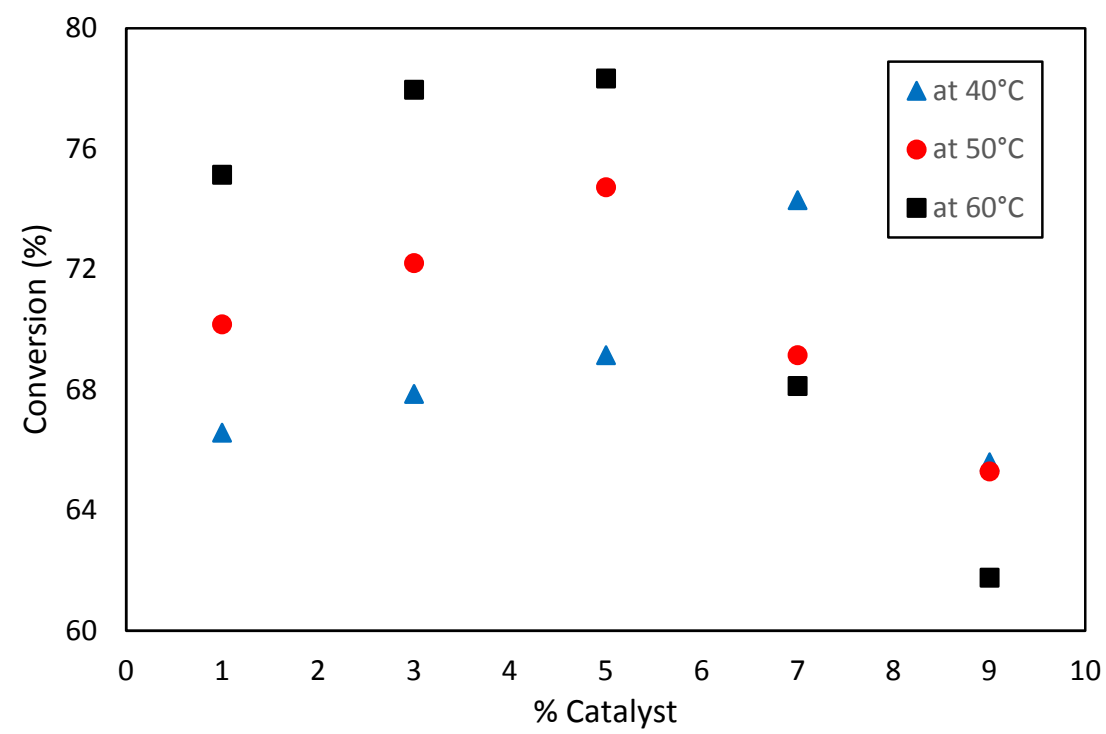

Figure 2: FFA conversion at different catalyst concentrations and reaction temperatures.

\subsection{Simulation Results}

Simulation of RD for the esterification of mixed non-edible has been conducted in ASPEN PLUS V8.8. Required information to run the simulation is presented in Table 1, 2 and 3. Stream results of the RD simulation are shown in Table 5.

The FFA conversion resulted from the simulation was determined based on the stream data presented in Table 5. It was found that the optimum FFA conversion obtained from the simulation was $75.8 \%$. Compared with the optimum conversion in the experimental study (78.3\%), FFA conversion on the simulation has an error of $3.19 \%$. This indicates that result of the simulation was closed to the experimental data, meaning that the model used in this simulation is valid and can accurately predict the conversion of FFA in the esterification of non-edible oil mixture. 
Table 5: Feed and product compositions resulted from the RD simulation.

\begin{tabular}{lcc}
\hline Component & Input $\left(\mathrm{kmole}^{-1}\right)$ & Output $\left(\mathrm{kmole} \mathrm{h}^{-1}\right)$ \\
\hline Oleic acid & 0.0421 & 0.0101 \\
Linoleic acid & 0.02 & 0.0048 \\
Palmitic acid & 0.0291 & 0.007 \\
Stearic acid & 0.009 & 0.0021 \\
Methanol & 6.012 & 5.9362 \\
Methyl oleate & 0 & 0.0319 \\
Methyl linoleate & 0 & 0.0152 \\
Methyl palmitate & 0 & 0.022 \\
Methyl stearate & 0 & 0.0068 \\
\hline
\end{tabular}

In this study, a sensitivity analysis was also performed to observe the effect of methanol:oil molar ratio to the FFA conversion. Figure 3 shows that the increase of the methanol:oil molar ratio will increase the FFA conversion. This phenomenon was in accordance with the results of research by Gan et al. ${ }^{13}$ The research reported that the increase of the mole ratio of methanol to oil would lower the viscosity of the reactants mixture, optimise the process of mixing and mass transfer, so that it will increase the conversion.

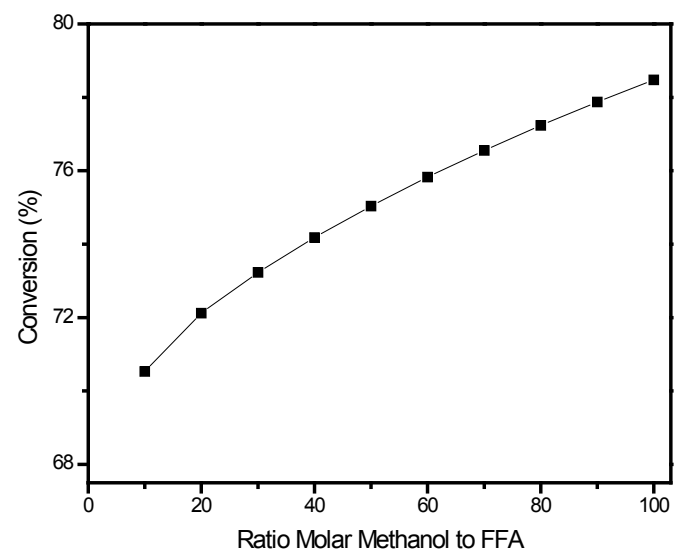

Figure 3: Effect of methanol:oil molar ratio to the FFA conversion. 


\section{CONCLUSION}

The esterification reaction of FFA by methanol is a slow and reversible reaction. Hence, the addition of catalyst is important to enhance the reaction rate and the application of RD was beneficial to shift the equilibrium to the product formation. To predict the RD performance at large scale operation, an accurate model and simulation is needed. Accurate model and process simulation can be obtained through model validation using experimental data. In this work, the experimental data shows that the optimal FFA conversion of $78.33 \%$ was obtained with the addition of catalyst concentration of $5 \%(\mathrm{w} / \mathrm{w})$ oil and the reaction temperature of $60^{\circ} \mathrm{C}$. On the other hand, FFA conversion achieved from simulation study using ASPEN PLUS V8.8 was $75.8 \%$. It can be concluded that the model used in the simulation has accurately predicted the FFA conversion of mixed non-edible oil in reactive distillation. Meanwhile, the results of sensitivity study indicates that the FFA conversion will increase by increasing the methanol:FFA molar ratio.

\section{ACKNOWLEDGEMENTS}

The authors thank all parties which have been supporting this research work. The authors also would like to thank the Indonesia's Ministry of Research, Technology and Higher Education for the financial support through Hibah Bersaing Research Grant with reference number of 675/UN37.3.1/LT/2016.

\section{REFERENCES}

1. Said, M., Septiarty, W. \& Tutiwi, T. (2010). Studi kinetika reaksi pada metanolisis minyak jarak pagar. J. Tek. Kim., 1(17), 15-22.

2. Furlan, C. \& Mortarino, C. (2018). Forecasting the impact of renewable energies in competition with non-renewable sources. Renew. Sust. Energ. Rev., 81, 1879-1886.

3. Kusumaningtyas, R. D. et al. (2016). Application of tin(II) chloride catalyst for high FFA jatropha oil esterification in continuous reactive distillation column. B. Chem. React. Eng. Cat., 11(1), 66-74.

4. Banchero, M., Kusumaningtyas, R. D. \& Gozzelino, G. (2014). Reactive distillation in the intensification of oleic acid esterification with methanol A simulation case-study. J. Ind. Eng. Chem., 20, 4242-4249.

5. Ramadhas, A. S., Jayaraj, S. \& Muraleedharan, C. (2005). Biodiesel production from high FFA rubber seed oil. Fuel, 84, 335-340. 
6. Kawentar, W. A. \& Budiman, A. (2013). Synthesis of biodiesel from secondused cooking oil. Energy Proced., 32, 190-199.

7. Fadhlullah, M., Widiyanto, S. N. B. \& Restiawaty, E. (2015). The potential of nyamplung (Calophyllum inophyllum L.) seed oil as biodiesel feedstock: Effect of seed moisture content and particle size on oil yield. Energy Proced., $68,177-185$.

8. Hidayat, A. et al. (2015). Esterification of palm fatty acid distillate with high amount of free fatty acids using coconut shell char based catalyst. Energy Proced., 75, 969-974.

9. Kusumaningtyas, R. D. et al. (2014). Graphical energy analysis of reactive distillation column for biodiesel production. Int. J. Energy, 15(4), 447-467.

10. Kusumaningtyas, R. D. et al. (2014). Tin (II) chloride catalyzed esterification of high FFA jatropha oil: Experimental and kinetics study. Int. J. Renew. Energy Dev., 3(2), 75-81.

11. Bhatia, S. et al. (2007). Production of isopropyl palmitate in a catalytic distillation column: Comparison between experimental and simulation studies. Com. Chem Eng., 31, 1187-1198.

12. Supardan, M. D. \& Satriana, S. (2009). Esterification of free fatty acid in crude palm oil off grade. J. Rekay. Lingku., 7(2), 70-74.

13. Gan, S. et al. (2010). Ferric sulphate catalysed esterification of free fatty acids in waste cooking oil. Biores. Technol., 101, 7338-7343.

14. Ferreira, A. B., Cardoso, A. L. \& Silva, M. J. (2012). Tin-catalyzed esterification and transesterification reactions: A review. Int. Scholarly Res. Netw., article ID 142857, https://doi.org/10.5402/2012/142857.

15. Srilatha, K. et al. (2009). Esterification of free fatty acids for biodiesel production over heteropoly tungstate supported on niobia catalysts. Appl. Catal. A-Gen., 365, 28-33.

16. Senania, A, Sulistyo, H. \& Prasetya, A. (2017). The synthesis of glycerol carbonate from biodiesel byproduct glycerol and urea over amberlyst 36 . JBAT, 6(1), 1-5. 